\title{
Reflexões sobre a educação física e suas crises em busca do status científico ${ }^{1}$
}

\author{
Reflections about physical education and its crisis in search of \\ the scientific status
}

Carlos Nazareno Ferreira Borges ${ }^{2}$

Renan Santos Furtado ${ }^{3}$

\section{RESUMO}

Trata-se de um ensaio de reflexão teórica a respeito da relação histórica entre a educação física e a ciência, tanto na Europa como no Brasil. Temos como objetivo central expor a partir de qual concepção de ciência as práticas corporais se difundiram na modernidade. Nosso estudo caracteriza-se por ser uma reflexão a partir de uma literatura já elaborada, portanto, um estudo bibliográfico. Como resultados principais, apontamos a vasta relação entre o positivismo e a educação física ao longo da história, o que se fez presente desde a construção da educação física como área de intervenção e disciplina escolar na Europa no século XIX com a proliferação dos métodos de ginástica.Como também na constituição da educação física brasileira a partir das influências europeias presentes no projeto moderno de dominação dos corpos dos sujeitos. Assim, concluímos que essa imbricação entre educação física e ciência ajudou no atraso histórico nos campos da formação profissional, na produção do conhecimento da área e nas práticas no campo da escola.

${ }^{1} \mathrm{O}$ presente trabalho não contou com apoio financeiro de nenhuma natureza para sua realização.

${ }^{2}$ Possui Graduação (Licenciatura Plena) em Educação Física pela Fundação Educacional do Estado do Pará (1990) e Graduação (Bacharelado) em Ciências Sociais pela Universidade Federal do Espírito Santo (2011); Mestrado (2000) e Doutorado (2005) em Educação Física pela Universidade Gama Filho; Pós-doutorado em Memória Social pela Universidade Federal do Estado do Rio de Janeiro (UNIRIO). Atualmente é docente associado IV da Universidade Federal do Pará, atuando na graduação em Educação Física e Pedagogia. É docente do Programa de Pós Graduação em Educação da Universidade Federal do Pará (PPGED/UFPA), atuando na linha de Formação de professores, trabalho docente, teorias e práticas educativas. ${ }^{3}$ Graduado em Licenciatura em Educação Física pela Universidade Federal do Pará (UFPA) no ano de 2017. Especialista em Educação Física escolar pela Escola Superior Madre Celeste (ESMAC) no ano de 2018. Mestrando em Educação pelo Programa de Pós-Graduação em Educação da UFPA (PPGED) com exame de qualificação realizado. Professor da Escola de Aplicação da Universidade Federal do Pará. Professor da SEDUC/PA entre 2017 e 2018. Membro do Centro Avançado de Estudos em Educação e Educação Física (CAÊ), integrando a linha de pesquisa: Estudos de Formação e Práticas Pedagógicas em Educação e Educação Física. Bolsista do Programa Institucional de Bolsa de Iniciação a Docência (PIBID), de 2014 a 2017.

Interfaces da Educ., Paranaíba, v.10, n.28, p. 168 à 188, 2019 ISSN 2177-7691 
Palavras-chave: Educação Física. Ciência. Práticas corporais.

\section{ABSTRACT}

It is a theoretical reflection on the historical relationship between physical education and science, both in Europe and in Brazil. We have as a central objective to expose from what conception of science the corporal practices spread in modernity. Our study is characterized by being a reflection from an already elaborated literature, therefore, a bibliographic study. As a main result, we point to the vast relationship between positivism and physical education throughout history, which has been present since the construction of physical education as an area of intervention and school discipline in Europe in the nineteenth century with the proliferation of gymnastic methods. As well as in the constitution of Brazilian physical education from the European influences present in the modern project of domination of the subjects' bodies. Thus, we conclude that this imbrication between physical education and science has helped in the historical backwardness in the fields of vocational training, in the production of the knowledge of the area and in the practices in the field of the school.

Keywords: Physical Education. Science. Corporal practices.

\section{Introdução}

Neste ensaio, procuramos discutir a relação histórica da educação física com aspectos da ciência e da cientificidade, buscando compreender o teor das práticas científicas elaboradas tanto para intervenção com as práticas corporais, como na pesquisa e produção do conhecimento na educação física.Portanto, a partir da consideração de Santos (2018) da ciência moderna como uma atividade dominada pela racionalidade instrumental fundada a partir do domínio do capital sobre as forças produtivas (força de trabalho humana mais os meios de produção), objetivando a construção de leis, regularidades e quantificações das esferas da vida, tentaremos identificar o perfil de atividade científica que orientou o desenvolvimento da educação física nesse período histórico.

Nosso estudo caracteriza-se por ser uma revisão e reflexão a partir de uma literatura já elaborada, ou seja, um estudo bibliográfico (SEVERINO,2002). Selecionamos textos que tratam da construção histórica da educação física, e confrontamo-los com referenciais da teoria social que 
dialogam sobre as concepções de ciência fundadas na modernidade, mais especificamente sobre o positivismo.

Estruturalmente organizamos este ensaio em dois momentos. Sendo o primeiro de contextualização histórica da educação física na modernidade, e a sua forma científica no período de sua constituição enquanto disciplina escolar a área de conhecimento. Em seguida, discutiremos um pouco a respeito da configuração da educação fisica na sociedade brasileira e a sua relação com a ciência e as instituições formativas.

\section{Os capitulos primários da relação entre educação física e ciência na modernidade}

Buscaremos brevemente destacar a partir de um recorte da modernidade, mais especificamente entre os séculos XIX e XX, apontamentos iniciais das tipologias de práticas científicas da educação física. Berman (1986) define a modernidade como a etapa histórica que tem seus germes no começo do século XVI, apogeu no século XIX, e continuidade em nosso tempo. Para o escritor trata-se de um período de intensas mudanças e metamorfoses no espírito e na sociabilidade humana, um verdadeiro turbilhão constante de possibilidades e contradições que colocam a prova todo o conjunto de certezas que a sociedade feudal construiu. Certamente é uma etapa de revoluções, de novas tradições, da industrialização da produção, do avanço das tecnologias, das grandes descobertas das ciências físicas, enfim, do constante risco ou possibilidade da criação da barbárie ou liberdade efetiva, justamente porque, como diriam Marx e Engels "Tudo o que era sólido se desmancha no ar" (2010, p. 43).

Fazendo uso das abstrações de Konder (2009a), precisamos fazer uma análise dialética do próprio sentido histórico da ciência e do seu papel para o desenvolvimento da humanidade na superação das barreiras do conhecer, pois, negar essa potencialidade seria um tanto quanto retrógrado politicamente e socialmente reacionário. Porém, também não podemos ter uma postura ingênua em relação ao desenvolvimento das ciências. Sendo assim, ergue-se a tarefa de reflexão crítica sobre a produção do saber, para 
assim, não a cultuarmos sem nenhuma forma de criticidade e aceitarmos diversas maneiras de ideologias e de imposições de qualquer tipo.

A partir de Adorno (1995), precisamos compreender a ciência moderna como sintese de uma sociedade cada vez mais administrada por grupos dominantes e pautada na superprodução de mercadorias, ou seja, a função da ciência tem sido a de contribuir para a dominação dos sujeitos,além da proliferação da miséria e da barbaria da civilização. Portanto, a partir da lógica de pensamento do autor supracitado, o progresso da ciência não tem sido proporcional ao desenvolvimento das potencialidades humanas dos sujeitos, fato esse que somente pode ser compreendido a partir do olhar para a evolução histórica desse processo.

O sentido de buscar a história nesse momento não se confunde com o objetivo de contar detalhadamente cada fato ou processo que constituíram a educação física brasileira. Trata-se de um esforço certamente arriscado de recorrer à história para encontrar nela os condicionantes significativos para o debate da ciência e campos científicos na área da educação física. Isso não quer dizer a negação de uma série de determinantes sociais que agiram e persuadiram esse "conto", e sim, a incorporação dialética e reconhecimento deles como totalidades mais abrangentes e processos mediadores do objeto a ser saturado no plano das abstrações do concreto.

Como sabemos, a década de 80 do século passado representou certa etapa de transição ou crítica no campo acadêmico e educacional da educação física (BRACHT, 2014). No entanto, o que se questionou nesse período, somente pode ser compreendido a partir da releitura de processos históricos determinados, sendo esse, justamente o objeto de nossa reflexão. Porém, queremos pensar especificamente a relação entre o desenvolvimento histórico das práticas corporais até a década de 80do século XX e o padrão de ciência utilizado para tal.

Daolio (1997) afirma que muitos processos anteriores ajudaram no dito período de contestação que a década de 80 aspirou em professores e acadêmicos na área da educação física. Em especial, passaremos mais fortemente por alguns deles buscando compreender a forma de irradiação de 
um tipo de pensamento que controlava a educação fisica nos trâmites políticos, educacionais e da própria produção do conhecimento.

Mas então, em que "linhas ou contextos" estão às raízes desse tipo de prática? O que caracteriza essas expressões corporais como utilitárias e acríticas? Quais motivos fizeram a comunidade da educação física pensar que deveriamos refletir sobre nosso modelo de atuação profissional e até mesmo formação de professores para uma efetiva transformação da educação física brasileira? Como se deram as primeiras aproximações entre a educação física e a ciência na modernidade?

Soares (2007) apresenta os determinantes sociais do surgimento da educação física na modernidade, e sua ligação com um projeto de consolidação de poder da classe burguesa européia principalmente do século XIX. Para essa perpetuação não bastava o controle das forças produtivas e propriedades dos meios de produção, ou seja, do produto e processo do trabalho da fábrica capitalista. Era necessário imputar valores, disseminar certas ideologias e controlar instituições diversas que surgem nesse momento.

A dinâmica do capitalismo exigiu a produção de um novo tipo de homem, adequado àquele novo padrão social, capaz de reproduzir e proliferar uma lógica política e moral. À educação física restava uma função: cuidar do corpo, enquanto instrumento do trabalho e amortizar qualquer possibilidade de intelecto crítico. Reforçava-se dessa forma,o não entendimento por parte de uma grande massa social do processo de dominação presente no continente europeu. Sobre essa relação entre mundo do capital e práticas corporais, apresentamos a passagem abaixo:

É nesta perspectiva que podemos entender a Educação Física como a disciplina necessária a ser viabilizada em todas as instâncias, de todas as formas, em todos os espaços onde poderia ser efetivada a construção deste homem novo: no campo, na fábrica, na família, na escola. A Educação Física será a própria expressão física do capital. Ela encarna e expressa os gestos automatizados, disciplinados, e se faz protagonista de um corpo "saudável", torna-se receita e remédio para curar os homens de sua letargia, indolência, preguiça, imoralidade, e, desse modo, passa a integrar o discurso médico, pedagógico... familiar (SOARES, 2007, p. 6). 
Ainda segundo Soares (2007), sendo o corpo dos individuos mais um instrumento da produção, passava a constituir uma preocupação da classe dominante. Tornava-se primordial nele investir,no entanto, tal investimento deveria ser no sentido de adestrar e dominar condutas. Era preciso docilizar o corpo, e lhe desenvolver o vigor desde cedo, para assim prepará-lo à sua função da produção e reprodução no mundo do capital.

De acordo com Soares (2011), a educação física é herdeira de uma tradição politica que valoriza principalmente a ordem e a disciplina, sendo o discurso do poder sobre o corpo na forma do cuidado com a higiene e aptidão dos indivíduos um dos seus elementos fundamentais. Assim, o corpo passou a ser compreendido como um objeto de intervenção da ciência moderna, como uma máquina a ser manipulada a partir de sabres das áreas médicas (anatomia, mecânica e fisiologia) para a vida produtiva.

Marx e Engels (2010) expressam quanto o poder da burguesia tende a se tornar global. Talvez a ideia de mundo globalizado, sem fronteiras, e com a lógica da perversidade fabulizada e mascarada como nos fala Milton Santos (2001), esteja contida nos escritos de Marx e Engels. Isso, porque, segundo os autores: "Impelida pela necessidade de mercados sempre novos, a burguesia invade todo o globo terrestre. Necessita estabelecer-se em toda parte, explorar em toda parte, criar vínculos em toda parte" (MARX; ENGELS, 2010, p. 43).

Sabemos que o escrito acima foi produzido durante o "olho do furacão" no século XIX (1848), no momento da constituição ferrenha da luta de classes entre burgueses e proletários.Nesse contexto, observamos a percepção dos teóricos que o confronto de classes tende a ser primeiramente uma questão mundial e em segundo plano. Trata-se de uma forma de compreensão muito além de análise do modo de exploração de forças produtivas de uma determinada sociedade, exercida via controle do trabalho e da produção de bens materiais por um determinado grupo social.

A categoria luta de classes aparece como um conjunto amplo de relações que vão se proliferando dentro da sociedade civil e do Estado. O surgimento do Estado burguês mostra a irradiação da noção de luta de classes.Assim, às instituições que compõem ou não o dito e a família, por exemplo, passam a 
expressar esse sentido amplo de relações sociais apresentados por Marx e Engels (2010).

Fica evidente que a noção de luta de classes é um conceito chave, não apenas para entendermos o nosso tempo, mas, ao que parece, "A história de todas as sociedades até hoje existentes é a história da luta de classes" (MARX; ENGELS, 2010, p.42). Luta de classes para esses teóricos não pode ser vista vulgarmente como duelo momentâneo entre duas classes pela direção da sociedade civil e do Estado político. Ou como costumeiramente ouvirmos falar, luta entre opressores e oprimidos. A luta de classes é antes de tudo uma forma contraditória e antagônica de relação social que vem garantindo a proliferação e o desenvolvimento de muitas sociedades.

É importante ressaltar o caráter contraditório de toda a história da humanidade até hoje conhecida. A contradição é um elemento do próprio movimento histórico. É muito maior, por exemplo, que o antagonismo, ou seja, a desigualdade natural entre classes sociais gerada no sistema de valorização do mundo das coisas entre as classes sociais coexistentes. De certo, o antagonismo de classes é uma contradição que precisamos eliminar das relações cotidianas. Contudo,projetar o término das contradições é correr em sentido contrário ao próprio movimento histórico e potencial criativo de homens e mulheres diversos e plurais (KONDER, 2009b).

E a educação física como se tratou brevemente acima, tem seus primeiros passos sistematizados metodologicamente no bojo daquela constituição social europeia. Ato contínuo, passou a ser difundida como parte do ordenamento burguês a todo o globo, adquirindo formas diferentes, porém, com utilidades bem similares. Os métodos ginásticos, ou escolas europeias de ginástica, aparecem como a primeira forma sistematizada desse novo tipo de prática corporal. Aqueles métodos expressavam uma espécie de ethos, ou seja, forma de ser do indivíduo e da sociabilidade burguesa por via de atividades corporais e exercícios físicos diversos. Assim, tais métodos expressavam a própria forma científica da educação física na modernidade, ou melhor, o sentido regulatório e metódico dessa nova "tradição". 
Tomando em recorte apenas o Método Ginástico Francês, recorremos a Soares (2005) para elucidar como se deu a relação entre ciência e ginástica. O método francês inicialmente foi construído por Francisco Amoros, o qual curiosamente começou sua sistematização junto à aristocracia espanhola, mas deu coro a seus novos parâmetros de ciência e racionalismo positivista na França, com os burgueses aristocratas durante a década de 20 do século XIX. A percepção e concepção de ginástica contida nas obras de Amoros e em sua intervenção no conjunto da esfera social da época denotavam todo o sentido dessa nova sociedade. Segue abaixo uma expressão sintética dessa forma de pensamento.

[...] a ciência fundamentada de nossos movimentos, de suas relações com nossos sentidos, nossa inteligência, nossos sentimentos, nossos costumes, e o desenvolvimento de todas as faculdades. A ginástica abarca a prática de todos os exercícios que tendem a tornar o homem mais corajoso, mais intrépido, mais inteligente, mais sensivel, mais forte, mais astuto, mais desembaraçado, mais veloz, mais flexivel e mais ágil e que nos dispõem a resistir a todas as intermpéries das estações, a todas as variações climáticas; a suportar todas as privações e contrariedades da vida; a vencer todas as dificuldades; a triunfar sobre todos os perigos e todos os obstáculos; a prestar, enfim, serviços de destaque ao Estado e à humanidade. A beneficência e a utilidade pública são o objetivo principal da ginástica; a prática de todas as virtudes sociais, de todos os sacrificios, os mais dificeis e os mais generosos são seus meios; e a saúde, o prolongamento da vida, o aprimoramento da espécie humana, o aumento da força e riqueza individual e pública são seus resultados positivos (AMOROS, apud SOARES, 2005, p. 37-38).

Do trecho citado podemos extrair interessantes sinteses sobre o ideário de prática corporal a qual a ginástica representava para Amoros. Primeiro sua identificação junto a noções da própria ciência, e como fica evidente, da ciência positivista. Ditavam-se as regras do jogo científico e das formas de analisar e intervir na nova sociedade. Parecia se alastrar o mesmo ideário 
observado nas fábricas, onde a ideia era a produtividade, o racionalizar para melhor explorar sujeitos castigados de miséria física e espiritual.

O quadro de exploração comentado foi descrito por Marx (2010), segundo o qual esses mencionados "castigos" ocorriam como necessários à acumulação de capital, miserabilizando o próprio sentido do gênero humano. Amoros não ameniza palavras para dizer o caráter utilitário da moralidade burguesa que a ginástica deveria assumir, além de seu papel de submissão ao Estado e à vida pública controlada pela Aristocracia e seguidamente pelos burgueses.

Um pequeno excurso na discussão das bases da filosofia positivista mostra a ampla convergência dessa forma de ciência e o discurso de Amoros. Andery et al.(2014), apresentam algumas características marcantes dessa concepção de mundo a partir de um diálogo direto com a obra de seu percussor, o Francês Augusto Comte (1798-1857). Segundo os autores, para Comte, trata-se de criar uma doutrina capaz de proliferar a ciência dos fenômenos naturais e sociais, tratando de elucidar manifestações imediatas e explicá-las a partir de leis únicas, imutáveis e gerais para toda a humanidade.

É ainda Andery et al.(2014) a nos informar que a vida humana para Comte se desenvolve em três estados ${ }^{4}$ ou fases (teleologia, metafísica e positiva) e, a história tem suas leis para seu desenvolvimento harmônico e individual. Assim, servem os sujeitos apenas como perpetuadores da espécie, não podendo atrapalhar a ordem social estabelecida pelas instituições políticas. As mudanças devem ser graduais e ordenadas, sendo a radicalidade de uma revolução estrutural erradicada do imaginário social. Acaba sendo melhor, primeiramente, mudar os indivíduos antes das estruturas sociais,

\footnotetext{
${ }^{4}$ Andery et al, (2014)afirmam que Comte ver o desenvolvimento da história e do pensamento humana a partir da passagem obrigatória por dois estados, até a chagada ao estágio positivo. Nos estágios teológicos e metafísicos da razão humana os agentes sobrenaturais e entidades supremas ainda são preponderantes na forma de pensar da humanidade. Porém, no estágio positivo o reconhecimento da religião universal da humanidade, do progresso da ciência não como explicação absoluta e historicamente provada, mas sim como eficaz e fática na explicação imediata de fenômenos e das leis do mundo objetivo passam a conotar as características de um novo estágio fundando na manipulação objetiva e racional do ser humano sobre os fatos sociais.
} 
educar moralmente para a vivência de costumes sadios e da chamada religião da humanidade.

Por fim, os mesmos autores mencionados acima afirmam que o conhecimento científico para Comte passa a ser baseado na observação direta dos fatos que são estabelecidos pelo raciocínio humano, excluindo tentativas de descobertas das possiveis origens ou causas primeiras das manifestações sociais ou naturais.

A ginástica, explicitamente nas palavras de Amoros e nas elaborações seguintes das outras escolas europeias, passa a ser toda a maneira de exercitar e moldar o corpo. Da mesma forma,desenvolve características e, principalmente conceitos e valores no campo do pensamento de homens e mulheres a serviço e compromisso de progresso social da sociedade. Por meio de tantas funções sociais, a ginástica se desenvolvia para reproduzir o formato positivista de desenvolvimento humano.

Justificam-se nos movimentos ginásticos do século XIX,os discursos da moralidade, do nacionalismo, civismo e coragem, como fins de práticas que desenvolvem a agilidade, força e resistência.Os novos ordenamentos sociais, a crença na razão cientificista e desenvolvimento do metabolismo social burguês, colocavam a tarefa da educação moral do corpo para a educação física.

Podemos inferir a partir da análise dessa sistematização da educação física (ginástica), e da sua forma nessa época, que os objetivos e fins da prática não apontam nesse momento para o acúmulo do potencial cultural e formativo humanista das diversas práticas corporais que faziam parte de um programa ginástico. O que se aponta é para o desenvolvimento de características sempre fora da própria atividade. É como se a atividade corporal realizada tivesse fim na moralidade e no modo de pensar dominante da própria sociedade que a recebia. Deste modo, o positivismo parece ter sido a filosofia perfeita para fundamentar o uso social das práticas físicas.

Um grande exemplo disso tudo são as primeiras sistematizações de métodos ou escolas de ginástica, como nos mostra Soares (2007), ao tratar da escola alemã, sueca e francesa.Marinho (2010) a partir de elaborações de 
Alberto Langlade, descreve as características das escolas alemã, nórdica e inglesa. O mais curioso é que tanto Soares, como Marinho nos apontam o tipo de prática que se consolidou na Inglaterra como uma forma de ginástica ou escola.

Porém, a partir de estudos principalmente de Bracht (2005) e Stigger (2005), notamos que o fenômeno ali teve peculiaridades singulares. Estamos falando do surgimento do dito esporte moderno, ou simplesmente esporte, na linha teórica defendida pelos autores, muito influenciados por Norbert Elias e Eric Dunning (1992) na obra "A busca da excitação".

Assim, Embora inserido no mesmo contexto e com os próprios objetivos dos métodos tradicionais de ginástica difundidos na Europa, o esporte moderno, ou simplesmente o esporte apresenta e ganha contornos próprios no seu desenvolvimento histórico como sinalizam Bracht (2005) e Stigger (2005). Estamos falando de uma atividade humana que ao padronizar e se apropriar da cultura lúdica existente até então principalmente na Inglaterra, funda uma nova forma de prazer e dispêndio de energia em uma atividade corporal específica. Um novo tipo de jogo capaz de em seu ato preservar o lúdico e o competitivo, a tensão e o divertimento, o choro e o riso. Enfim, a nova excitação é tão ampla e atrativa que também se tornou capaz de manipular, controlar e segmentar grupos sociais ao longo da história.

Com as passagens acima a respeito das formas de ser da ginástica em cada nação da Europa, queremos chegar ao sentido da sistematização e do funcionamento dessas práticas corporais, em um singular período da história da humanidade, para isso trazemos Soares novamente. A autora nos diz que:

Apresentando algumas particularidades a partir do país de origem, essas escolas, de um modo geral, possuem finalidades semelhantes: regenerar a raça (não nos esqueçamos o grande número de mortos e de doença); promover a saúde (sem alterar as condições de vida); desenvolver a vontade a coragem, a força, a energia de viver (para servir a pátria nas guerras e na indústria) e, finalmente, desenvolver a moral (que nada mais é do que uma intervenção nas tradições e costumes dos povos) (2007, p. 52). 
Bracht (2014) sinaliza que a forma científica ou de teorização da educação física nesse momento foi feita com premissas pedagógicas, tanto médicas, como morais. As práticas corporais se apresentavam como formas de educação para a saúde ou vida cotidiana, logo, a atividade teórica e de sistematização se fundamentava diretamente por via de referências da biologia e demais áreas médicas. As práticas se manifestavam, assim, como uma atividade do plano da ação, sempre pensada por intelectuais de outras áreas.

Lovisolo (1998) afirma que em sua história, a educação física adentra no nivel superior a partir de um conceito ou forma de curso profissionalizante. Desse modo, vinculada diretamente a um fazer técnico para determinadas funcionalidades econômicas, politicas e sociais. Os saberes práticos que, por exemplo, Amoros realizava sem possuir uma determinada formação para tal, passaram a ser aprendidos em cursos de formação superior principalmente a partir do século XX no Brasil.

Podemos perceber uma intensa relação entre um conjunto de instituições e interesses econômicos com o tipo de teorização que se firmou na educação física em sua constituição moderna. Bracht (2014)argumenta que a própria formação de intelectuais da área dispostos a intervir criticamente para o avanço dela, teve seus dias retardados. Dessa forma, a educação física ficou refém de um intenso colonialismo epistemológico advindo das ditas ciências consolidadas (Fisiologia, Anatomia, Medicina e etc.).

Portanto, a partir da consideração da lógica de expansão do capital e de suas formas ideológicas por todo o globo, como afirma Soares (2007) à educação física brasileira acaba por ser fruto do projeto de poder instituído na Europa. Desse modo, no que pese certas diferenças, a relação entre a educação física e a ciência no Brasil apresenta em enredo similar à trajetória dramática do continente europeu. No próximo tópico, buscaremos estreitar a proximidade nas relações entre a educação física e ciência no Brasil.

\section{A constituição de um ideário e pensamento que "marca" a educação física brasileira}

Interfaces da Educ., Paranaíba, v.10, n.28, p. 168 à 188, 2019 ISSN 2177-7691 
Vimos com Marx e Engels (2010) que é tendência do modo de produção capitalista a formação de um mercado mundial, capaz de explorar e difundir ideologias e instituições em todos os lugares do mundo. No Brasil, a cena da chegada da educação física não ganhou contornos tão diferentes. Junto aos interesses de reprodução social burguesa, a educação física é promulgada no conjunto de nossa sociedade como prática moralizadora de uma nova estrutura social.

O símbolo positivista de ordem e progresso encontra em práticas corporais organizadas e sistematizadas na Europa, sob a forma de ginástica, sua dimensão corporal e ideológica. Da mesma maneira que na Europa servia para todos os setores da sociedade como "higienização social", no Brasil, sua vinculação adquire status e função similar. O que muda é a particularidade em questão.Não esqueçamos que se tratava de um país que vivia ainda em regime de escravidão no século XIX, além de um desenvolvimento industrial reduzido e concentrado na região sudeste.

Essa afirmação de que o Brasil foi uma nação que vivenciou a escravidão até o ano de 1888, acarretou na própria dificuldade de aceitação inicial da educação física nas terras brasileiras. Pois, as práticas corporais acabavam por ser associadas às atividades ou ao tipo de trabalho realizado pelos escravos, sendo diferentes da educação intelectual que as elites dominantes ofertavam para os seus filhos. Assim, o processo de real consolidação da educação física por parte da burguesia nacional se deu principalmente a partir do século XX, devido à influência da expansão da escola básica e dos ideários médicos e militares que valorizavam a ginástica como forma de "cuidar" do corpo (CASTELLANI FILHO, 2011).

Outro elemento importante desse período, que nos remete também ao começo do século XIX, refere-se a forte força que as instituições militares tiverem para a consolidação da educação no Brasil. Alguns marcos históricos podem ser identificados como expoentes dessa relação entre a educação física e as instituições militares, como, por exemplo, a criação da Escola Militar pela Carta Régia de 4 de dezembro de 1810, que recebeu o nome de Academia Real Militar. Também podemos citara introdução da ginástica alemã no ano de 
1860 por via da nomeação do Alferes do Estado maior de segunda classe, o alemão Pedro Guilhermino Meyer, para a função de contramestre da ginástica militar (CASTELLANI FILHO, 2011).

É marcante também no século de XIX, o parecer de $n^{\circ} 224$ de 12 de setembro de 1882 de Rui Barbosa. Nesse parecer, a educação física ganhou um capítulo próprio, fato que já apontava a importância que sua prática viria a ter nos anos seguintes. De acordo com Soares (2007) foi a partir desse documento que a educação física passou a fazer parte do currículo escolar, sendo a ginástica sueca, que se baseava em uma concepção médico-higienista, seu principal conteúdo.

Anos a frente, outros marcos nos ajudam a identificar a valorização da educação física na sociedade brasileira, como, por exemplo:a instalação da Associação Cristã de Moços no Rio de Janeiro em 1891; a criação da Escola de educação física da Força Policial de São Paulo em 1909; a edição de revistas e congressos da educação física de caráter higienista; além da promulgação por Washington Luís, do método Frances de Ginástica, como o método oficial do Brasil (GORDO ET AL, 2014).

Nessa perspectiva, Castellani Filho (2011) observa que a educação física adentra no Brasil com grande influência das instituições militares e dos pensamentos médico e higienista. Inicialmente,os métodos alemão e francês representaram a tonalidade dessa prática que passou a adentrar as escolas brasileiras como obrigatória nas redes primárias e secundárias. Obrigatoriedade essa que se deu a partir da lei constitucional n.1 da Constituição dos Estados Unidos do Brasil, de 10 de novembro de 1937.

O Estado Novo (1937-1945) não só consolidou a burguesia incipiente, como também um modelo de práticas físicas aos moldes de ciências como anatomia e fisiologia, capazes de normatizar a noção do homem como máquina a ser adestrada (CASTELLANI FILHO, 2011). A burguesia continua seu projeto de poder e dominação na sociedade brasileira ao longo de todo o século XX. O esporte passa a ser, também como tendência internacional, o grande agente da educação física a partir das décadas 40 e 50, atingindo seu ápice na década de 60, principalmente após a segunda guerra mundial, sendo 
extremamente influente no sistema escolar nacional. Um pouco dessa legitimidade esportiva no cenário mundial e nacional pode ser observada com a passagem a seguir:

Após a segunda guerra mundial, que coincide com o fim da ditadura e do estado novo no Brasil, surgem outras tendências disputando a supremacia no interior da instituição escolar. Destaca-se o método natural austriaco desenvolvido por Gaulhofer e Striecher e o método da Educação Física Desportiva Generalizada, divulgado no Brasil por Auguste Listello. Predomina nesse último a influência do esporte que, no período do pós-guerra, apresenta um grande desenvolvimento, afirmando-se paulatinamente em todos os países sob a influência da cultura europeia como elemento predominante da cultura corporal (COLETIVO DE AUTORES, 2012, p. 53).

A educação física, como Bracht (1997) aponta no texto: "A criança que pratica esporte, respeita as regras do jogo... capitalista", quando adota o esporte, adota o modelo de alto rendimento, exacerba o desempenho e valoriza códigos da sociedade burguesa. O autor diz que, no fundo:

Se analisarmos as aulas de Educação Física onde o esporte escolar é iniciado e desenvolvido, veremos que a idéia da aprendizagem do esporte enquanto aprendizagem das técnicas esportivas predomina. Isto porque, para a competição, na verdade, é isto que conta. Permeia, portanto, a busca do rendimento atlético-esportivo, que é condição para as possibilidades de vitória nas competições (BRACHT, 1997, p. 63).

A interpretação desta passagem deve ser considerada em seu marco temporal. O esporte adotava para a escola o modelo das instituições esportivas. Nesse sentido, a "caça” de talentos e o desenvolvimento de capacidades físicas por meio de sua prática, eram objetivos da educação física escolar. O rendimento físico e motor passaram a ser o parâmetro avaliativo atrelado ao desempenho como elemento seletivo e de teor das atividades realizadas (COLETIVO DE AUTORES, 2012).

Não é por acaso, que como mostra Ghiraldelli Junior (1991), pela resolução de número (18/2/1971), o governo introduziu para as escolas de $1^{\circ}$ e $2^{\circ}$ graus a possibilidade de criação de turmas de treinamento. Por esse procedimento, mostrava-se uma forma de concepção da própria educação 
física no interior da escola, baseada na seleção e no desenvolvimento de talentos esportivos para servir à nação. O esporte realmente exercia e talvez ainda exerça uma hegemonia nas aulas de educação física.

Nesse sentido, temos para a teorização e campo científico da área uma nova dimensão. É nesse momento como mostra Bracht (2014), a partir principalmente da década de 60, que o discurso sai do plano meramente pedagógico normativo, para algo de cunho fortemente cientificista. Foi assim que, no sentido negativo de apologia à ciência, passou-se a questionar se a educação física era ou não uma ciência. Isso se deu principalmente póssegunda guerra mundial, muito no impulso da realidade de outros países (Alemanha, Canadá, etc.), nos quais o debate já havia se constituído bem antes.

Bracht (2014) aponta que esse período entre as décadas de 60 e 70, é crucial para o campo acadêmico e científico da educação física no Brasil. É nesse período que o esporte passa a ser a grande figura da nova possibilidade de ascensão e status social para a própria educação física. Até a denominação que surge nesse momento, de ciências do esporte, na tentativa de substituir o termo;Educação Física, demonstra os rumos perigosos e reducionistas que se pretendiam para a união entre educação física e ciência.

Foi nesse cenário descrito acima, por exemplo, com a apresentação do diagnóstico da educação física/Desportos no Brasil, que se observaram as deficiências na produção teórica sobre a medicina esportiva no país, sendo necessário o aumento de investimentos em pesquisas e incentivo para a pósgraduação e laboratórios qualificados. É nesse mesmo contexto que o próprio Colégio Brasileiro de Ciências do Esporte é fundado no final da década de 70 . Daólio (1997) aprofunda esse debate mostrando o domínio dos médicos e fisiologistas sobre a entidade em suas primeiras gestões, ficando fáticos os rumos que ela poderia tomar com o cientificismo esportivista.

Queríamos mostrar com as breves passagens acima o momento de hegemonia desse tipo de atividade corporal (esporte), e como ele passa a ser socialmente consolidado como sinônimo de educação física. A expansão de mídias sociais, grandes torneios mundiais, os chamados megaeventos 
esportivos, marcas esportivas globais, heróis nacionais e popularização de certos esportes, ajudam e ajudaram a materializar esse pensamento presente de certa forma até nossos dias, mesmo que com muitas críticas de várias correntes de pensamento na área.

Sobre a questão da internacionalização e expansão do esporte principalmente a partir da segunda metade do século XX, Tubino $(1999 ; 2011)$ apresenta elementos e marcos fundamentais desse processo a nível internacional. Embora possamos ter fortes críticas às obras citadas, nelas o leitor pode encontrar de forma coesa e direta quais momentos históricos e fatores denotam as características do processo de crescimento do fenômeno esportivo em dimensão global, o que consequentemente acarretou no aumento de estudos a partir de diversas ciências sobre as práticas esportivas (medicina, sociologia, psicologia e etc.).

Feitas tais discussões, sinalizamos que a reflexão por nós desenvolvida quis mostrar que do ponto de vista da formação humana multifacetada tratada por Marx (2010), da defesa da apropriação irrestrita do patrimônio histórico cultural da humanidade como direito de todos, ocorreram prejuízos históricos no desenvolvimento da educação física no Brasil. A história dessa área do conhecimento - educação fisica - insere-se em um circuito trágico de ordem moral, cívica e reprodutora de toda lógica de dominação e exploração de uma classe social sobre outra. Os diversos modelos de práticas corporais serviram de base para a consolidação de um projeto da classe burguesa da época, classe essa que em primeiro momento foi revolucionária, e hoje pode levar a humanidade à barbárie civilizatória e à destruição de todas as classes.

Em sintese, a nós parece que a história da educação física até hoje conhecida tem sido a história da legitimação por meio das práticas corporais da exploração planejada da classe burguesa sobre o restante das organizações sociais que tratam com a cultura corporal. Escolas, clubes, instituições e centros de lazer vêm contribuindo de modo controlado e racionalizado para a construção de consenso passivo entre as classes.

Isso não significa dizer que nunca tivemos resistência crítica mediante estes processos de dominação. A exemplo citamos Ghiraldelli Junior (1991), 
ao identificar as tendências históricas da educação física brasileira, comenta a respeito de uma educação física popular. Essa seria uma proposta de corrente ligada com os setores subalternos da sociedade e também dos movimentos revolucionários, os quais buscavam modelos alternativos de práticas corporais e principalmente sua servidão às camadas populares de forma prazerosa e lúdica.

\section{Considerações finais}

Retornando o objetivo principal desse estudo de discutir a relação histórica entre a educação física e a ciência na Europa e na sociedade brasileira até a década de 80 do século passado, sinalizarmos que existiu e persiste ainda na educação física brasileira uma relação direta com a racionalidade positivista instaurada pela ciência moderna e com as práticas corporais fundadas nesse período. Assim, as conexões entre a educação física e a ciência na Europa e no Brasil se consolidaram a partir de uma noção restrita de ser humano, fazendo com que o corpo dos sujeitos fosse um meio apenas para a educação do físico em sentido restrito, não reconhecendo aspectos sociais, culturais e políticos da educação.

Vejamos de novo o título do último tópico que apresentamos: a constituição de um ideário e pensamento que "marca" a educação física. A palavra marca faz alusão justamente ao sentido de um ferimento, sinal no corpo, ou melhor dizendo, um golpe, uma marca daquelas que faz parte de nossa história e que carregamos até nossos dias, o peso de todos esses processos no cotidiano de nossas práticas e intervenções.

Muitos dos pensamentos, valores, dilemas e ações motoras promulgadas e vangloriadas há certo tempo ainda se fazem presente em escolas, cursos de formação superior e outros espaços de práticas corporais. Evidentemente não superamos por incorporação crítica a filosofia positivista e suas inserções em diversos campos da educação física brasileira. Realmente a ferida foi profunda, e paradoxalmente despertou os germes de sua possível superação, o que fez da década de 80 do século passado, o momento de ebulição das críticas históricas, pedagógicas e estruturais da área. 
Cabe também salientar, que todo esse processo de negação de outras possibilidades para a educação física e dominação da lógica positivista fizeram com que o próprio desenvolvimento da área se tornasse refém desse processo. Logo, não consideramos factual, a ainda associação por parte de grande parcela da população da educação física com a educação do físico, e não como uma atividade com potencial emancipatório.

O exposto parece-nos suficiente por ora, para considerar que, historicamente, a educação fisica se relacionou com o positivismo, e tal fato ajudou no atraso histórico em campos como, a formação profissional, a educação física escolar e a produção do conhecimento na área.

\section{Referências}

ADORNO, T. Educação e Emancipação. Rio de Janeiro: Paz e Terra, 1995.

ANDERY, M. A. et al.Para Compreender a ciência:uma perspectiva histórica. Rio de Janeiro: Garamond, 2014.

BERMAN, M. Tudo o que é sólido desmancha no ar: A aventura da modernidade. São Paulo: Editora SchwarczLtda,1986.

BRACHT, V. Educação Física \& ciência: cenas de um casamento (in) feliz. 4. ed. unijuí, 2014.

BRACHT, V. Educação Física e aprendizagem social. 2. ed. Porto Alegre:Magister, 1997. 122p.

BRACHT, V. Sociologia crítica do esporte: uma introdução. 3. ed. Coleção Educação física. Ijui: Editora Unijuí, 2005.

CASTELLANI FILHO, L. Educação física no Brasil:a história que não se conta. 19. ed. Campinas: Papirus, 2011.

COLETIVO DE AUTORES. Metodologia do ensino de educação física. São Paulo: Cortez, 2012.

DAOLIO, J. Educação Física brasileira:autores e atores da década de 80. São Paulo: Campina, 1997.

DUNNING, E; NOBERT, E. A busca da excitação. Lisboa, Difel, 1992. 
GHIRALDELLI, P. Educação Física progressista: A Pedagogia Crítico-Social dos Conteúdos e a Educação Física Brasileira. 3. ed. Edições Loyola, São Paulo: Brasil, 1991.

GORDO, M. et al. A história da Educação Física no Brasil e as suas bases legais. Belém: Editora Açaí, 2014.

KONDER, L. Marxismo e Alienação: contribuição para um estudo marxista do conceito de alienação. 2. ed. São Paulo, 2009(a).

KONDER, L. O Marxismo na batalha das ideias. 2. ed. São Paulo: Expressão popular, 2009(b).

LOVISOLO, H. Pós-Graduação e Educação Física: Paradoxos, tensões e diálogos. Revista Brasileira de Ciência do Esporte, Florianópolis, v.20, n.1, set/98.

MARINHO, Vitor. Educação fissica humanista. Rio de janeiro: Shape, 2010.

MARX, K. Manuscritos econômicos e filosóficos. São Paulo: Expressão popular, 2010.

MARX, K; ENGELS, F. Manifesto do partido comunista. São Paulo: Boitempo, 2010.

SANTOS, B. S. Um discurso sobre as ciências. São Paulo: Cortez, 2018.

SANTOS, M. Por uma outra globalização: do pensamento único a consciência universal. 6. ed. Rio de Janeiro: Recorde, 2001.

SEVERINO, A. J. Metodologia do trabalho científico. São Paulo: Cortez Editora, 2002.

SOARES, C. L. Corpo, conhecimento e educação. In: SOARES, C. L (org.). Corpo e História. Campinas: Autores Associados, 2011.

SOARES, C. L. Educação Física:Raízes Européias e Brasil. Campinas, SP: Autores Associados, 2007.

SOARES, C. L. Imagens da Educação no corpo. Estudo da ginástica francesa no século XIX. Campinas, SP: Autores Associados, 2005.

STIGGER, M. P. Educação Física, esporte e diversidade. Campinas, SP: Autores Associados, 2005.

TUBINO, M. G. Dimensões sociais do esporte.3. ed. São Paulo: Cortez, 2011. 
TUBINO, M. G. O que é Esporte.São Paulo: Brasiliense, 1999. 